Disponível em: http://periodicos.ufpb.br/ojs2/index.php/recfin

\title{
PRÁTICAS CONTÁBEIS ADOTADAS POR ENTIDADES DO TERCEIRO SE- TOR: UMA ANÁLISE JUNTO A TEMPLOS RELIGIOSOS DE PERNAMBUCO À LUZ DA ITG 2002
}

\section{ACCOUNTING PRACTICES ADOPTED BY THIRD SECTOR ENTITIES: AN ANAL- YSIS NEXT TO RELIGIOUS TEMPLES OF PERNAMBUCO IN THE LIGHT OF ITG 2002}

\section{Priscila Karla Ferreira da Silva ${ }^{1}$}

Mestranda em Ciências Contábeis pela Universidade Federal de Pernambuco pri.kfs@gmail.com

\section{José Jonas Alves Correia}

Mestrando em Ciências Contábeis pela Universidade Federal de Pernambuco jhonnasallves@hotmail.com

\section{Andreza Cristiane Silva de Lima}

Mestranda em Ciências Contábeis pela Universidade Federal de Pernambuco andrezacslima@gmail.com

\section{Filipe Emmanuel Alves da Silva}

Mestrando em Ciências Contábeis pela Universidade Federal de Pernambuco felipeemmanuel@hotmail.com

\section{Luiz Carlos Miranda}

Ph.D em Agronegócios pela Universidade de Illinois

Professor do Programa de Pós-graduação em Ciências Contábeis da Universidade Federal de Pernambuco mirandaphd@gmail.com

\section{RESUMO}

Objetivo: Este estudo teve como objetivo verificar o grau de aderência das entidades religiosas, quanto à ITG 2002, em suas práticas contábeis.

Fundamento: As entidades religiosas, embora não obrigadas a publicarem seus relatórios contábeis de prestação de contas, quando optarem por elaborar e divulgar suas demonstrações, devem seguir

\footnotetext{
1 Artigo recebido em: 15/01/2017. Revisado por pares em: 08/05/2017. Reformulado em: 07/07/2017. Recomendado para publicação em: 24/07/2017 por Adriana Fernandes de Vasconcelos (Editora Adjunta). Publicado em: 10/08/2017. Organização responsável pelo periódico: UFPB.

${ }^{1}$ Endereço: Av. Prof. Moraes Rego, 1235 - Cidade Universitária, Recife - PE - CEP: 50670-901.

DOI: http://dx.doi.org/10.18405/recfin20170307
} 
as normas e recomendações do Conselho Federal de Contabilidade (CFC) para a elaboração das demonstrações contábeis. Os templos, como pessoas jurídicas de direito privado sem finalidade de lucros, devem seguir a ITG 2002, documento aprovado pela Resolução CFC nº 1.409/2012.

Método: Foram estudadas as demonstrações contábeis de quinze templos religiosos do Estado de Pernambuco, sendo a escolha realizada por critério de conveniência. A coleta de dados se deu através da técnica de survey, com aplicação de um questionário semiestruturado, visando observar se as práticas contábeis adotadas pelas entidades estavam em conformidade com a norma. ITG 2002 Para analisar os dados adotou-se o procedimento de análise de conteúdo.

Resultados: A pesquisa revelou que as práticas contábeis adotadas pelas entidades religiosas do Estado de Pernambuco não estão totalmente em conformidade com a Interpretação Técnica pertinente (ITG 2002). Há, portanto, oportunidade para os templos religiosos adotarem boas práticas no âmbito contábil e gerencial. Embora a aplicação deste normativo não seja obrigatório por lei, sua utilização pode contribuir para aumentar a transparência e a accountability dessas entidades, já que elas são mantidas por meio de doações.

Contribuições: O estudo é relevante porque permite que se conheçam as práticas contábeis adotadas pelos templos religiosos e também por revelar que há oportunidades para melhorias na prestação de contas dessas entidades para seus constituintes e provedores de recursos.

Palavras-chave: Entidades Sem Fins Lucrativos. Entidades Religiosas. Práticas Contábeis. ITG 2002.

\section{ABSTRACT}

Objective: This study aimed to verify the degree of adherence of religious entities to ITG 2002 in their accounting practices.

Background: Religious entities, although not required by law to publish their accounting reports, when they choose to disclose their financial statements this must be done in accordance with the standards and recommendations of the Federal Accounting Council (CFC) for the preparation of the financial statements. Religious temples, as non-profit entities must follow ITG 2002, the norm approved by CFC Resolution № 1409/2012.

Method: The study was conducted in the State of Pernambuco. The accounting statements of fifteen religious temples were studied, being the choice made by criterion of convenience. The data collection was done his through the survey technique, with application of a semistructured questionnaire, aiming to observe if the accounting practices adopted by the entities were in conformity with the norm. To analyze the data we selected the content analysis procedure.

Results: The survey revealed that the accounting practices adopted by the religious entities of the State of Pernambuco are not fully in accordance with the relevant Technical Interpretation (ITG 2002). Therefore, there is an opportunity for religious temples to adopt good practices in accounting and management. Although the application of this standard is not mandatory by law, its use can contribute to increase the transparency and accountability of these entities, as they are maintained through donations.

Contributions: The study is relevant because it allow us to know the accounting practices adopted by religious temples and also because it reveals that there are opportunities for improvements in the accountability of these entities to their constituents and providers of resources.

Keywords: Non-Profit Entities. Religious Entities. Accounting Practices. ITG 2002. 


\section{INTRODUÇÃO}

A Contabilidade passou a ser observada não apenas como uma técnica de registro das mutações patrimoniais, mas também como um fenômeno social (Buchell, Clubb \& Hopwood, 1985). Nesse sentido, os autores destacam que, dentro do contexto social, a contabilidade se tornou um instrumento usado para fins gerenciais e de suporte às mudanças que ocorrem em um ambiente coletivo, portanto, as alterações que incidiram em torno dessa ciência objetivaram relacionar as questões sociais às econômicas, o que contempla uma visão mais ampla do funcionamento das organizações.

Falar da relação entre contabilidade e questões sociais traz à tona a discussão da contabilidade como uma ciência social aplicada, cuja função é identificar mecanismos de mensuração, a fim de registrar os objetos patrimoniais, levando em consideração suas características quantitativas e qualitativas, e apresentar informações que sejam utilizadas no ambiente social. Portanto, cabe à sociedade compreender tal ciência como um instrumento que fornece informações e presta contas às partes interessadas (Coliath, 2014). Sendo assim, esta pesquisa explora essa interrelação através de uma análise contextual da utilização da contabilidade nas entidades religiosas.

Para o ordenamento jurídico brasileiro, as entidades religiosas, mais conhecidas como igrejas, são consideradas pessoas jurídicas de direito privado. A lei no 10.825, de 22 de dezembro de 2003, que dá nova redação aos arts. 44 e 2.031 da lei no 10.406, de 10 de janeiro de 2002, contida no Código Civil, diz que sua diretoria estatutária responde judicialmente pelos danos causados à Instituição de Fé, aos membros e a terceiros, atribuindo, portanto, responsabilidade aos gestores dessas entidades.

A base da contabilidade do terceiro setor é a estrutura patrimonial definida pela Lei 6.404/1976 (Lei das Sociedades por Ações), e as demonstrações financeiras referentes a essas entidades possuem peculiaridades, por isso, apresentam normas que orientam como esses documentos devem ser elaborados. Complementarmente, Araújo (2005, p. 54) aponta que, por possuírem essas particularidades, "existem normas de preparação e apresentação de demonstrações contábeis, bem como de divulgação, e que essas devem ser seguidas pelos profissionais que lidam com a contabilidade dessas organizações". Nesse sentido, destaca-se a questão da preparação dos profissionais, quanto ao conhecimento das práticas contábeis desse tipo de entidade, para que possam suprir as necessidades informacionais dos interessados na situação patrimonial, financeira e de gestão destas entidades.

Os templos religiosos, na posição de pessoas jurídicas de direito privado, sem finalidade de lucros, necessitam prestar contas às partes interessadas em seu desempenho (stakeholders) e no que se refere às informações econômico-financeiras, em atendimento à função da contabilidade como ciência social. Para esse alcance, essas entidades devem utilizar as Normas Brasileiras de Contabilidade, especificamente, a ITG 2002 - Entidade Sem Finalidade de Lucros (ESFL), Interpretação Técnica Geral, que orienta o atendimento às exigências legais sobre procedimentos contábeis a serem cumpridos, especialmente, pelas entidades imunes, isentas de impostos e contribuições para a seguridade social. Sendo assim, a contabilidade nos templos religiosos torna-se essencial, não somente para demonstrar a origem dos recursos e a forma como eles foram aplicados, mas também para validar, juridicamente, os atos financeiros da entidade (Oliveira \& Romão, 2011).

Alguns escândalos de corrupção ocorridos em entidades religiosas de várias crenças, tais como o caso da Igreja Maranata no Espírito Santo (Fernandes, 2016); o caso do Vaticano, retratado no livro "Avarizia" do jornalista Emiliano Fittipaldi (EFE, 2015) e o caso da Igreja Renascer, ocasionam dúvidas quanto à administração dos recursos financeiros que as igrejas recebem dos seus fieis (Folha de São Paulo, 2010), algo que motivou Corrêa e Vale (2017), a realizarem um estudo cujo objetivo foi de comparar a atividade religiosa a um mercado econômico. 
Diante desse cenário, a contabilidade se torna um mecanismo capaz de mostrar o emprego dos recursos que são captados através dos fiéis, e, portanto, se torna um instrumento de comprovação da sua seriedade (Boedau \& Lima, 2008), fato que traz a oportunidade de conhecer como tais entidades divulgam como seus recursos estão sendo utilizados. Diante dessa discussão, este estudo visa responder a seguinte questão-problema: qual é o grau de aderência das entidades religiosas do Estado de Pernambuco, quanto à ITG 2002, em suas práticas contábeis?

O estudo justifica-se por vários fatores, dentre os quais, por averiguar o nível da utilização das práticas contábeis pelas entidades religiosas do Estado de Pernambuco. Com isso, é possível identificar o grau de importância que pode estar sendo atribuída ou não, pelos líderes religiosos, quanto à prestação de contas dos recursos que utilizam para manutenção de suas atividades, recursos esses oriundos de doações de seus fiéis.

Espera-se que este estudo contribua para um melhor conhecimento sobre as práticas contábeis dos templos religiosos, assunto já tratado por outros autores (Gomes, 2000; Paixão \& Lourenço, 1994; Laughlin, 1988; Hardy \& Ballis, 2013; Ihemeje, Okereafor\&Ogungbangbe, 2015).

Este artigo está dividido em cinco seções, sendo esta primeira a introdução do tema, onde o assunto é contextualizado e o objetivo da pesquisa apresentado. Na segunda seção apresenta-se a fundamentação teórica, onde, por meio de estudos anteriores, apresenta-se o aporte teórico sobre as entidades sem fins lucrativos, entidades religiosas e as práticas contábeis que estas devem seguir, com base na ITG 2002. Em sequência, expõem-se os procedimentos metodológicos que viabilizaram a execução da pesquisa, cujos resultados são evidenciados e discutidos na quarta seção. Na quinta e última seção, apresentam-se as conclusões, limitações e sugestões de pesquisas futuras.

\section{FUNDAMENTAÇÃO TEÓRICA}

\subsection{Entidades Sem Fins Lucrativos}

O termo entidades sem fins lucrativos, usado para atribuir às entidades que não se enquadram no contexto do Estado e do mercado (que agrupa as entidades de fins econômicos), por si só, não reflete o seu desempenho dentro do contexto social, econômico e político (Olak \& Nascimento, 2009). Apenas a utilização da expressão "sem finalidade de lucros", não implica necessariamente em dizer que uma instituição tenha o objetivo de atuar em prol de benefícios sociais, sendo necessário entender o propósito do surgimento de cada entidade que se classifica como do terceiro setor.

Para Mendonça e Machado Filho (2004), o terceiro setor é um conjunto de atividades privadas que têm finalidade pública, cuja atuação ocorre sem o intuito de lucro, e pode ser composto por instituições civis de qualquer origem. Adicionalmente, este setor se diferencia da lógica estrita de governo e de mercado, que são o primeiro e segundo setor, sendo este privado com fins lucrativos e àquele público com finalidade de prestar serviços públicos em atendimento às necessidades comuns da população (Camargo, 2001).

Segundo Olak e Nascimento (2009), no Brasil, a colocação dos termos “Terceiro Setor, Organizações Não Governamentais (ONGs), Organizações da Sociedade Civil, Organizações Sociais, Entidades Beneficentes, Organizações Filantrópicas" e demais instituições desta natureza, acontece de forma precipitada, pois muitas vezes são usadas como sinônimos, o que implica muito mais nas divergências quanto à compreensão da finalidade dessas instituições. Além destas, mais duas entidades passaram a integrar o grupo: as Organizações Sociais (OS), criadas através da reforma administrativa das funcionalidades do Estado, e, as Organizações da Sociedade Civil de Interesse Público, mais conhecidas por OSCIPs, as quais foram constituídas com a publicação da Lei nº 9.790, de 23/03/99.

A expressão Organização não Governamental (ONG), de acordo com Falconer (1999), foi introduzida no Brasil por meio da Conferência Rio-92, momento que propiciou discussões acerca de 
várias temáticas envolvendo assuntos voltados ao meio ambiente, defesa de direitos humanos e organização da participação social, esta última, a fim de contribuir no incentivo às atividades voluntárias. Portanto, o evento abarcou áreas que até então eram pouco trazidas e intensificadas pelas ONGs.

As ONGs, por sua vez, têm um significado que vai além do seu status legal de associação sem fins lucrativos, sendo necessário compreender os aspectos implícitos ao termo, tais como seu campo e sua forma de atuação, os quais contemplam o atendimento à sociedade na promoção da defesa dos direitos, através de atividades de assessoria e captação de movimentos populares. Segundo Falconer (1999), essas atividades são melhores apresentadas quando o termo advocacy é evidenciado, o que implica na mobilização popular, articulação política, conscientização e propagação de informações, ou seja, quando se fala em organizações que não têm a finalidade de lucros, é necessário identificar se estas têm o objetivo de suprir demandas sociais que até então não foram atendidas pelo poder público. Para caracterizar as entidades sem fins lucrativos, Freeman e Shoulders (1993), apontaram quatro particularidades, dentre as quais estão:

a) Em relação ao lucro: a razão pela qual tais entidades existem, não é a obtenção de lucro, e sim, atender lacunas sociais;

b) Em relação à propriedade: elas são de domínio da comunidade, por conta disso, não se apresentam como as propriedades privadas, cujo capital pode ser dividido em partes proporcionais;

c) Em relação à fonte de recursos: a captação de recursos ocorre por meio de doações, e aqueles se tornam patrocinadores, não adquirem o direito de participar de forma compensatória nos serviços ou bens da entidade;

d) Em relação às principais decisões políticas: as principais tomadas de decisões ocorrem em reunião, através do consenso do grupo e maior concentração de votos.

Resgatando à discussão sobre o tratamento do terceiro setor, no Brasil, a expressão vigente, até mesmo por força dos diversos dispositivos contemplados na legislação pertinente, sempre foi "entidades sem fins lucrativos". Na contabilidade, a ITG (Interpretação Técnica Geral) 2002, emitida pelo Conselho Federal de Contabilidade (CFC, 2012), em seu item 3, estabelece que uma entidade que não possui finalidade de lucro, exerce atividades relacionadas às áreas de assistência social, saúde, educação, técnico-científica, esportiva, religiosa, política, cultural, beneficente e social, sempre gerindo pessoas, coisas e fatos, cujo interesse exista e que o intuito seja o bem comum. Ao decorrer deste tópico, apresentaram-se várias classificações de entidades sem fins lucrativos, mas que, para este estudo delimitou-se em abordar apenas as entidades religiosas, as quais serão exploradas no tópico a seguir.

\subsection{Entidades Religiosas}

O Direito Canônico afirmava que a Igreja era uma sociedade autônoma, que podia se autogovernar, e que era autossuficiente para atingir seus objetivos (Oliveira \& Romão, 2001). O Código Civil (Brasil, 2002), estabelece em seu art. 44, que as entidades religiosas são livres de criação, sendo o poder público impossibilitado de negar sua existência e funcionamento. Assim, as igrejas podem se auto regulamentar, definir sua estrutura interna e organização, no entanto, isso não quer dizer que as organizações religiosas podem negligenciar a estrutura jurídica imposta pelo Código Civil, pois em casos de demanda judicial as entidades religiosas também respondem em juízo.

A contabilidade é única e o que muda são as especificações nas quais ela é usada. Quando se trata de templos religiosos, existe norma contábil específica para as entidades sem fins lucrativos: a ITG 2002, orientando que tais entidades devem utilizar dos princípios de contabilidade, para a qual também se aplica a NBC TG 1000, que trata de contabilidade para pequenas e médias empresas, pois 
a mesma apresenta informações sobre como deve ocorrer o tratamento contábil para entidades dessa natureza.

Os registros contábeis das ESFL devem ser feitos seguindo as Normas, Resoluções e os Princípios de Contabilidade. Os Princípios de Contabilidade representam a essência das doutrinas e teorias relativas à Ciência da Contabilidade, consoante o entendimento predominante nos universos científico e profissional de nosso país. Concernem, pois, à contabilidade no seu sentido mais amplo de ciência social, cujo objeto é o patrimônio das entidades (Faveroet al., 2011).

Com a finalidade de explorar como devem ocorrer as práticas contábeis expressas pela ITG 2002, o tópico a seguir apresenta um levantamento dos principais pontos que as entidades sem fins lucrativos devem observar no momento de elaborar seus respectivos demonstrativos contábeis.

\subsection{Práticas Contábeis segundo a Interpretação Técnica Geral (ITG) 2002}

As entidades sem finalidade de lucros (ESFL) são aquelas em que o resultado positivo não é destinado aos detentores do patrimônio líquido e o lucro ou prejuízo são denominados, respectivamente, de superávit ou déficit (CFC, 2012). Todas as ESFL, mesmo as que tenham sede no exterior e que atuem no Brasil, devem seguir as normas contábeis brasileiras.

A ITG 2002 foi aprovada pela Resolução CFC no 1.409/12, emitida em 21/09/2012, e passou a ser aplicável para os exercícios sociais iniciados a partir de $1^{\mathrm{o}}$ de janeiro de 2012. Ela estabelece critérios e procedimentos específicos de avaliação, de reconhecimento das transações e variações patrimoniais, de estruturação das demonstrações contábeis e as informações mínimas a serem divulgadas em notas explicativas de entidade sem finalidade de lucros. Esta Instrução Técnica Geral apresenta itens específicos que devem ser observados pelos templos religiosos. Os tópicos tratados na referida norma são sobre: reconhecimento, registros contábeis, demonstrações contábeis, contas de compensação e divulgação.

A Interpretação técnica que estabelece critérios e procedimentos específicos de avaliação, de registro das transações e variações patrimoniais, de estruturação das demonstrações contábeis, e as informações mínimas a serem divulgadas em notas explicativas da entidade sem finalidade de lucros é a ITG 2002, cujas demonstrações exigidas são: o Balanço Patrimonial, a Demonstração do Superávit ou Déficit do Período, a Demonstração das Mutações do Patrimônio Líquido e a Demonstração dos Fluxos de Caixa, conforme previsto na NBC TG 26 ou na seção 3 da NBC TG 1000, quando aplicável. Essas demonstrações têm o objetivo de auxiliar na divulgação das informações contábeis e financeiras destas entidades, são melhores evidenciadas no Quadro 1: 
Quadro 1: Finalidade das demonstrações contábeis aplicadas às entidades religiosas

\begin{tabular}{|c|c|}
\hline DEMONSTRAÇÃO & FINALIDADE \\
\hline Balanço Patrimonial & $\begin{array}{l}\text { Apresentar a posição financeira e patrimonial da entidade em determinada data, } \\
\text { representando, portanto, uma posição estática. Com base na Lei } n^{\circ} \text { - } 6.404 / 76 \text {, em seu } \\
\text { art. 178, nessa demonstração, as contas serão classificadas segundo os elementos do } \\
\text { patrimônio que registrem e agrupadas de modo a facilitar o conhecimento e a análise } \\
\text { da situação financeira da companhia. }\end{array}$ \\
\hline $\begin{array}{l}\text { Demonstração do } \\
\text { Superávit ou Déficit do } \\
\text { Período }\end{array}$ & $\begin{array}{l}\text { Evidenciar todas as atividades desenvolvidas pelos gestores relativas a um } \\
\text { determinado período de tempo, denominado de "Período". A ênfase não deve ser } \\
\text { dada ao resultado (lucro/prejuízo), como ocorre nas entidades de fins lucrativos. Em } \\
\text { linhas gerais, para a entidade sem fins lucrativos, a preocupação maior é com as } \\
\text { atividades e/ou projetos desenvolvidos do que com o resultado. }\end{array}$ \\
\hline $\begin{array}{lr}\text { Demonstração } & \text { das } \\
\text { Mutações } & \text { do } \\
\text { Patrimônio Social } & \end{array}$ & $\begin{array}{l}\text { Informar, resumidamente toda a movimentação ocorrida com as contas integrantes } \\
\text { do Patrimônio Social, com base no saldo inicial do período anterior até o saldo final } \\
\text { do exercício, contendo, portanto, além da demonstração da conta Superávit ou Déficits } \\
\text { Acumulados, a demonstração do que ocorreu com as demais contas do Patrimônio } \\
\text { Social. }\end{array}$ \\
\hline $\begin{array}{l}\text { Demonstração } \\
\text { Fluxos de Caixa }\end{array}$ & $\begin{array}{l}\text { Mostrar como ocorreram as movimentações de disponibilidades em um dado período } \\
\text { de tempo. Essa demonstração é obrigatória pela Lei das Sociedades por ações, e o CFC } \\
\text { a tornou obrigatória para as demais sociedades. Divide todos os fluxos de entrada e } \\
\text { saída em três grupos: os derivados das atividades operacionais, das atividades de } \\
\text { investimento e das atividades de financiamento. }\end{array}$ \\
\hline Notas Explicativas & $\begin{array}{l}\text { Destacar e interpretar detalhes relevantes, informações adicionais sobre fatos } \\
\text { passados, presentes e futuros, significativos nos negócios, e resultados da entidade, } \\
\text { de importância para as pessoas nela interessadas. }\end{array}$ \\
\hline
\end{tabular}

Fonte: Elaborado com base em Iudícibus, Martins, Gelbcke \& Santos, 2010; Lei oํ⒍404/76; Olak \& Nascimento 2010.

Assim como a estática, a dinâmica patrimonial é representada por um conjunto de demonstrações contábeis, cada qual com finalidade específica, com o objetivo de apresentar a evolução dos fenômenos patrimoniais em determinado período, evidenciando as variações provenientes dos fatos ocorridos neste mesmo período (Favero et al., 2011).

O tópico reconhecimento da ITG 2002 trata de como devem ser reconhecidas as receitas, despesas e as doações e subvenções. O tópico registros contábeis da referida norma, trata da evidenciação, reconhecimento no resultado e do registro das contas de receitas e despesas, com ou sem gratuidade; do reconhecimento de forma segregada das contas patrimoniais e da constituição de provisão, e da incorporação do valor do superávit ou déficit ao Patrimônio Social. O tópico demonstrações contábeis, da ITG 2002, determina quais demonstrações devem ser elaboradas pela entidade sem finalidade de lucros, as quais contemplam o Balanço Patrimonial, a Demonstração do Superávit ou Déficit do Período, a Demonstração das Mutações do Patrimônio Líquido e a Demonstração dos Fluxos de Caixa, as substituições na denominação de algumas contas e ainda as informações que devem ser destacadas e divulgadas em notas explicativas por tipo de atividade.

Quanto ao tópico contas de compensação, a ITG 2002 esclarece que sem prejuízo das informações econômicas divulgadas nas demonstrações contábeis, a entidade pode controlar em conta de compensação transações referentes a isenções, gratuidades e outras informações para uma melhor evidenciação contábil. Quanto ao tópico divulgação, a norma fala das informações mínimas que as notas explicativas devem conter para complementar as demonstrações contábeis.

A ITG 2002 ainda esclarece que algumas nomenclaturas nas demonstrações das ESFL devem ser alteradas, como por exemplo: ao invés das contas "capital social", "lucros ou prejuízos acumulados" usem-se as nomenclaturas "Patrimônio Social" e "superávit e déficit do exercício" respectivamente. 


\subsection{Estudos Anteriores}

Através do levantamento e leitura dos estudos anteriores, identificaram-se as lacunas quanto às pesquisas que precisam ser realizadas a fim de melhor discutir a contabilidade e sua relevância dentro das entidades religiosas. Antes de tudo, destaca-se a pouca abordagem em torno do tema contabilidade aplicada ao terceiro setor, e quando se trata especificamente das entidades religiosas, essa carência ainda é bem maior, principalmente no âmbito nacional.

Ao resgatar a história da contabilidade em Portugal entre os séculos XII a XV, Gomes, 2000; Paixão e Lourenço (1994), afirmam que dentre os principais entes que utilizavam a contabilidade como instrumento de controle e decisão estavam as corporações religiosas, embora fossem empregadas técnicas simples que se resumiam, praticamente, a apresentação de receitas e despesas, as quais eram descritas de forma minuciosa nos documentos.

A pesquisa de Laughlin (1988), realizada em igrejas da Inglaterra, mostrou que o sistema de contabilidade paroquial é bastante básico e que precisa ser mais explorado. Essa precariedade do sistema contábil se dá pelo fato das igrejas não terem nenhum departamento ou pessoa responsável para desempenhar esta função. O autor aponta que quando são notadas práticas contábeis neste tipo de instituições, normalmente são conduzidas porque foram identificadas falhas no controle ou porque são obrigadas a elaborar tais relatórios em atendimento ao processo de prestação de contas.

Se tratando de prestação de contas, Hardy e Ballis (2013) examinaram os relatórios informais das instituições de caridade que operam como um departamento de uma igreja. Assim, o estudo revelou que, embora tal relatório personalizasse as fronteiras de comunicação, ou seja, deixassem as informações de forma clara aos seus usuários, tornando a linguagem mais simples de se compreender, eles também ajudavam a apresentar informações que iam além da prestação de contas, tais como informações referentes à própria gestão da instituição.

Nessa discussão, destaca-se a pesquisa de Themeje, Okereafor e Ogungbangbe (2015), os quais afirmam que um sistema de contabilidade deve ser adotado por esse tipo de organizações, pelo fato de aumentar a responsabilidade e transparência dos registros financeiros de suas atividades, mas que a atitude por parte da gestão das igrejas é bastante negativa, portanto, não dão importância a esse tipo de controle e gestão.

Diante do exposto, as pesquisa de Laughlin (1988), Hardy e Ballis (2013), Ihemeje, Okereafor e Ogungbangbe (2015), deixam claro a importância da utilização das práticas contábeis no processo de prestação de contas das entidades religiosas, mas que os próprios envolvidos na gestão dessas instituições não conseguem enxergar o quanto tal atividade é viável, principalmente para mostrar o impacto social que as mesmas estão trazendo à comunidade, já que fazem parte do terceiro setor, e como tal, têm o objetivo de preencher lacunas sociais que não são atendidas pelo poder público e privado, os quais englobam os primeiro e segundo setores da economia.

Ainda sobre prestação de contas, Portulhak, Delay e Pacheco (2015), apontam que esta é uma ferramenta que legitima e valida as ações que são exercidas pelos agentes envolvidos na organização, e se trata de um mecanismo capaz de ampliar a confiabilidade sobre a condução dos recursos financeiros, além de ser um procedimento que deve ser observado pelas entidades do terceiro setor, seja para atender órgãos regulamentadores, fiscalizadores ou auxiliar na captação de recursos.

Em se tratando de gestão, Soares, Vicente e Linkes (2010), apontam a importância do papel gerencial alcançado através da contabilidade dentro das instituições religiosas. Os autores pontuam que em virtude dos recentes escândalos de corrupção envolvendo entidades religiosas, no que tange a recursos não declarados e desvio de dinheiro captado através dos seguidores, surge a necessidade de haver controle interno como forma de assegurar os ativos que são destinados a tais entidades, o que implica na promoção da transparência quanto à aplicação desses recursos. 
Discutir a respeito do controle interno, remete às questões gerenciais, algo que contempla também o acompanhamento orçamentário. Assim sendo, Kothe, Souza e Gozer (2009) examinaram através de um estudo de caso, uma entidade religiosa, a fim de verificar se esta utilizava o orçamento para gerir as atividades financeiras, os projetos e no auxílio da captação de recursos. Os achados apontaram o uso do orçamento apenas na prevenção dos gastos das atividades operacionais, ainda que os gestores não enxergavam o orçamento como ferramenta para captar recursos e/ou tomar decisões. Esses resultados mostram a falta de conhecimento em relação à contribuição que um orçamento é capaz de trazer dentro de uma organização.

Em relação à transparência dos recursos, Faria e Rego (2014) verificaram a aplicabilidade de fatores que contribuíam com o nível de accountability exercido por uma entidade religiosa do município de Feira de Santana-BA. O estudo também observou se a contabilidade se configurava como ferramenta decisória no processo de transparência financeira. Os achados apontam que a entidade atua com transparência em suas finanças e que os fiéis e doadores, que também foram assistidos na pesquisa, diziam perceber a existência de prestação de contas dos recursos. No entanto, não opinavam quanto à destinação desses. Por sua vez, a divulgação da contabilidade para a comunidade se restringia aos demonstrativos de entradas, saídas e saldos, não divulgando as demais demonstrações, embora a entidade tivesse elaborado.

Nesse aspecto, identifica-se o assunto como um campo fértil de pesquisa, fato que motivou a realização deste estudo, o qual busca analisar se nas entidades religiosas de Pernambuco, no que tange à elaboração, divulgação das demonstrações contábeis e prestação de contas dos recursos ocorrem em observância à norma contábil específica que contempla as entidades religiosas. Sendo assim, o tópico a seguir, apresenta os aspectos metodológicos que tornaram este estudo possível.

\section{METODOLOGIA}

Em relação aos objetivos, a presente pesquisa caracteriza-se como exploratório-descritiva. Esse tipo de estudo, no primeiro momento, proporciona uma visão panorâmica do tema, em seguida descreve os fatos e fenômenos observados. Em investigações como essa, o pesquisador observa, registra e analisa de modo fiel a realidade investigada, sem intervenções e juízo de valor nessa descrição (Triviños, 1987).

Quanto à natureza dos dados e abordagem do problema, a pesquisa se configura como qualitativa. Segundo Vergara (2006, p. 257), "pesquisas qualitativas contemplam a subjetividade, a descoberta, a valorização da visão de mundo dos sujeitos. As amostras são intencionais, selecionadas por tipicidade ou por acessibilidade". Eminentemente qualitativo, este estudo buscou, através da aplicação de questionários, conhecer a realidade de um determinado tipo de entidade, as religiosas, para avaliar a dinâmica interna de processos e atividades, considerando as características destas organizações. A lógica da pesquisa é indutiva. A indução é o método recomendado quando se objetiva descrever realidades, fenômenos ou situações visando à elaboração de enunciados gerais (Saunders, Lewis \& Thornhill, 2016).

No que tange aos procedimentos técnicos de coleta de dados, a pesquisa designa-se como um survey e o instrumento de coleta de dados utilizado foi um questionário semiestruturado, validado e testado por uma doutora da área contábil. A coleta de dados foi realizada in loco e aplicada pelos próprios pesquisadores. Os questionários foram aplicados uma vez em cada entidade estudada, o que torna essa pesquisa transversal quanto à temporalidade. "Estudos transversais propõem-se a estudar um problema utilizando dados colhidos em diferentes subgrupos de pessoas que estejam em diferentes estágios de desenvolvimento" (Lehman \& Mehrens, 1971, p. 95).

A população da pesquisa é o conjunto das entidades religiosas do Estado de Pernambuco. Diante da dificuldade de acesso, foram escolhidas 15 dessas entidades, por critério de conveniência. Esse tipo de amostragem envolve na seleção dos casos, aqueles com maior acessibilidade pelo 
pesquisador (Saunders, Lewis \& Thornhill, 2016). Dessa forma, buscaram-se informações sobre as práticas contábeis utilizadas nos anos de 2012 e 2013, cuja escolha do período justifica-se pela instituição da norma (2012) e por eventuais impactos causados por ela nas práticas no ano seguinte.

Especificamente, as questões abrangentes do questionário foram divididas em dois blocos: o primeiro visou conhecer as características das entidades e foi composto por perguntas abertas e fechadas, conforme elencadas no Quadro 2. O segundo bloco trouxe os pontos introduzidos pela ITG 2002, os quais foram transformados em categorias (obrigações principais e acessórias, reconhecimento da informação contábil, registro contábil, elaboração das demonstrações contábeis e divulgação) para auxiliar na análise dos dados, e questionados aos respondentes (responsável pela contabilidade da igreja, seja contador, técnico em contabilidade, pastor, diácono ou tesoureiro). As questões objetivaram verificar se os responsáveis pela contabilidade estavam elaborando as demonstrações contábeis em conformidade com a norma. As 31 questões postas neste bloco deveriam ser respondidas em assertivas sim ou não.

Quadro 2: Bloco 1 do questionário - Caracterização das entidades religiosas

\begin{tabular}{|l|l|}
\hline \multicolumn{1}{|c|}{ Perguntas } & \multicolumn{1}{c|}{ Opções de Resposta } \\
\hline Forma de Governo & $\begin{array}{l}\text { Episcopal, Presbiteriano, Congregacional } \\
\text { Representativo. }\end{array}$ \\
\hline $\begin{array}{l}\text { Quantidade de membros que compões o Conselho } \\
\text { Fiscal }\end{array}$ & Pergunta aberta. \\
\hline Quantidade de membros & Pergunta aberta. \\
\hline Quantidade de templos em Recife & Pergunta aberta. \\
\hline $\begin{array}{l}\text { Quantidade de templos em Pernambuco ligados a } \\
\text { entidade }\end{array}$ & Pergunta aberta. \\
\hline Se a igreja faz parte de uma Convenção & Sim; Não. \\
\hline $\begin{array}{l}\text { Se existe um profissional com registro no CRC que } \\
\text { elabora as informações contábeis. }\end{array}$ & Sim; Não. \\
\hline
\end{tabular}

Fonte: Elaborado pelos autores.

Após a fase da coleta de dados, as respostas foram agrupadas de forma sistematizada. Para essa etapa da pesquisa, o procedimento utilizado foi a análise de conteúdo. A análise de conteúdo estabelece várias técnicas onde se procura descrever o conteúdo expresso no processo de comunicação, seja por meio de discursos ou de textos e compreende técnicas de pesquisa que permitem, de forma sistemática, a descrição das mensagens e das atitudes atreladas ao contexto da enunciação, bem como as inferências sobre os dados coletados (Bardin, 2007; Saunders, Lewis \& Thornhill, 2016). Desta forma, uma vez obtidas as respostas propostas no instrumento de coleta, analisaram-se os dados conforme as categorias criadas anteriormente. A análise e discussão dos resultados obtidos são expostas na seção seguinte.

\section{ANÁLISE E DISCUSSÃO DOS RESULTADOS}

Para analisar os resultados adotou-se o anonimato das entidades assistidas na pesquisa. $\mathrm{O}$ uso do anonimato ou confidencialidade na pesquisa qualitativa é utilizado quando a pessoa, grupos ou organizações, enquanto objeto do estudo, desejam manter proteção à sua identidade (Flick, 2009). Destarte, pela omissão das identidades dos templos religiosos, estabeleceram-se as letras " $\mathrm{A}$ ", " $\mathrm{B}$ ",

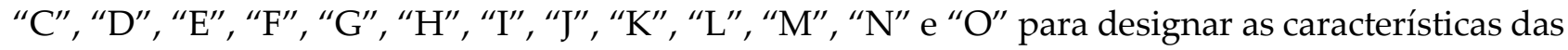
quinze organizações pesquisadas.

De acordo com o art. 150 da Constituição Federal de 1988 veda-se aos entes federais, estaduais ou municipais cobrar tributos dos templos religiosos de qualquer culto, com isso essas entidades gozam de imunidade tributária. No entanto, a carta magna não exime tais organizações da responsabilidade de apresentar suas obrigações acessórias, nem da obrigação principal quando 
esta for cabível, como é o caso da contribuição para PIS/PASEP, que incide sobre a folha de pagamento das organizações do terceiro setor (Art. 2º , Lei 9.715/98).

Nestes aspectos, o Quadro3 expõe os resultados da pesquisa concernente à categoria obrigações principais e acessórias. A obrigação demarcada por um " $\mathrm{X}$ " implica dizer que a mesma foi cumprida pela entidade no período do estudo, junto ao órgão competente. Caso o item da obrigação principal ou acessória não fosse atendido, não seria marcado.

Quadro 3: Categoria obrigações principais e acessórias

\begin{tabular}{|c|c|c|c|c|c|c|c|c|c|c|c|c|c|c|c|}
\hline \multirow{2}{*}{ Obrigação } & \multicolumn{15}{|c|}{ INSTITUIÇÕES } \\
\hline & $\mathbf{A}$ & B & $\mathrm{C}$ & D & E & $\mathbf{F}$ & G & $\mathbf{H}$ & I & $\mathrm{J}$ & $\mathrm{K}$ & $\mathbf{L}$ & $\mathbf{M}$ & $\mathbf{N}$ & $\mathrm{O}$ \\
\hline $\begin{array}{l}\text { Contribuição para o } \\
\text { PIS/PASEP }\end{array}$ & $X$ & $\mathrm{X}$ & & $x$ & & $\mathrm{X}$ & & $x$ & & $x$ & & $x$ & & $x$ & $\mathrm{x}$ \\
\hline DCTF & $X$ & & & & & $\mathrm{X}$ & & & & & & $x$ & & & $x$ \\
\hline DACON & $X$ & $\mathrm{X}$ & & & & $\mathrm{X}$ & & & $x$ & & & $x$ & $x$ & & \\
\hline DIPJ & $X$ & $\mathrm{X}$ & & $X$ & $x$ & $\mathrm{X}$ & & $x$ & $x$ & $x$ & & $x$ & $x$ & $x$ & $\mathrm{X}$ \\
\hline RAIS & $X$ & $\mathrm{X}$ & & $\mathrm{X}$ & $\mathrm{X}$ & $\mathrm{X}$ & & $X$ & $x$ & $x$ & & $x$ & $\mathrm{X}$ & $x$ & $\mathrm{X}$ \\
\hline GFIP & $\mathrm{x}$ & $\mathrm{X}$ & & $\mathrm{x}$ & $\mathrm{X}$ & $x$ & & $x$ & $\mathrm{X}$ & $x$ & & $X$ & $\mathrm{X}$ & $\mathrm{X}$ & $\mathrm{X}$ \\
\hline
\end{tabular}

Fonte: Dados da pesquisa.

Das entidades analisadas, quatro cumpriram todas as obrigações acessórias exigidas para obtenção da imunidade apontada na Constituição Federal (CF), isso corresponde a 26,67\%do total. Vale ressaltar que as organizações que fizeram o recolhimento da contribuição para o PIS/PASEP justificam-se pela existência de folha de pagamento interna. Percebeu-se que três igrejas não cumprem nenhuma das regras exigidas pela $\mathrm{CF}$, estas representam $20 \%$ do total, isso mostra que essas entidades gozam da imunidade tributária, mas não cumprem as regras impostas para tal.

Verificou-se que as 53,33\% restantes atendem ao menos a três das exigências (DIPJ, RAIS e GFIP), que também se deve ao fato da existência de folha de pagamento. Os relatos de Paixão e Lourenço (1994), Gomes (2000) e Ihemeje, Okereafor e Ogungbangbe (2015), convergem com os achados da pesquisa, ao passo que refletem, mesmo com o passar do tempo e com a evoluçãodas Ciências Contábeis e sua aplicabilidade social, que, embora exista contabilidade nas entidades religiosas, mesmo com técnicas simples, percebe-se que seus gestores não dão a devida importância à utilidade da contabilidade como ferramenta eficaz para uma boa gestão das atividades operacionais.

Outra categoria criada para analisar os dados foi quanto ao reconhecimento das informações contábeis por parte das entidades. Neste ponto, observou-se os itens 09 e 10 do instrumento de coleta: reconhecimento de receitas e despesas pelo regime de competência e as doações e subvençoes para custeio e investimento, respectivamente. Este último item é abarcado pelo NBC TG 07(R1) que dispõe sobre subvenção e assistência governamentais e enfatiza regras para o reconhecimento.

Quadro 4: Categoria reconhecimento

\begin{tabular}{|c|c|c|c|c|c|c|c|c|c|c|c|c|c|c|c|c|}
\hline \multirow[t]{2}{*}{ Item } & \multirow[t]{2}{*}{ Descrição } & \multicolumn{15}{|c|}{ INSTITUICCÕES } \\
\hline & & $\mathbf{A}$ & B & C & D & E & $\mathbf{F}$ & G & $\mathrm{H}$ & I & $\mathbf{J}$ & $\mathbf{K}$ & $\mathbf{L}$ & $\mathbf{M}$ & $\mathbf{N}$ & $\mathbf{O}$ \\
\hline 09 & $\begin{array}{l}\text { Receitas e despesas são } \\
\text { reconhecidas mensalmente } \\
\text { pelo regime de } \\
\text { competência. }\end{array}$ & $x$ & $x$ & & $X$ & $x$ & $x$ & & $x$ & & $x$ & & $x$ & $x$ & $x$ & \\
\hline 10 & $\begin{array}{l}\text { Doações e Subvenções para } \\
\text { custeio e investimento } \\
\text { reconhecidas como Receita } \\
\text { no resultado (NBC TG 07). }\end{array}$ & $\mathrm{x}$ & & & $\mathrm{x}$ & & $x$ & & $\mathrm{x}$ & & & & $\mathrm{x}$ & & & \\
\hline
\end{tabular}


Fonte: Dados da pesquisa.

Observa-se que dez entidades reconhecem mensalmente as receitas e despesas pelo regime de competência, isso representa aproximadamente $66,67 \%$ do total das igrejas. Os templos que foram designados por " $\mathrm{C}$ ", " $\mathrm{G}$ " e " $\mathrm{K}$ ", assim como não cumpriam as obrigações principais e acessórias, também exprimiram não fazer o devido reconhecimento de receitas, despesas, doações e subvenções. Depreende-se com isso, a existência de negligência por parte do gestor das entidades ou de um responsável contábil, pois mesmo que as igrejas estivessem inativas no período, deveriam enviar ao menos as obrigações acessórias. Duas entidades reconhecem as doações e subvenções para custeio e investimento como receita no resultado e três apenas as doações. As demais não apresentam estes fatos em suas operações.

A informação contábil se configura como uma fonte rica para auxiliar os gestores na tomada de decisões e a qualidade dada à informação remetida ao usuário pode fazer um diferencial na hora de decidir (Nascimento \& Reginato, 2008). Nas organizações do terceiro setor não é diferente. Em virtude disso, o tratamento dado aos registros contábeis nessas organizações, no seu momento tempestivo, coopera na transparência da entidade que é avaliada como uma estratégia de gestão e, é por meio da transparência que as organizações atestam de forma fiel quem são e quais os seus reais objetivos (Carneiro, Oliveira \& Torres, 2011).

Neste contexto, o registro contábil se torna uma atividade essencial nas práticas contábeis dos templos religiosos. Os resultados pertinentes a esta categoria de análise são apresentados em termos percentuais (como base nas quinze entidades) para cada item do questionário referente às práticas de registros em consonância com a ITG 2002, como mostra o Quadro 5.

Quadro 5: Categoria registros contábeis

\begin{tabular}{|c|c|c|}
\hline Item & Descrição & $\%$ \\
\hline 11 & Registram-se receitas e despesas (com ou sem gratuidade) segregadas por atividade. & 80 \\
\hline 12 & $\begin{array}{l}\text { Registra-se a subvenção, contribuição para custeio e investimento, isenção, incentivo fiscal em } \\
\text { conta do passivo até o reconhecimento no resultado. }\end{array}$ & 20 \\
\hline 13 & $\begin{array}{l}\text { Receitas e despesas para aplicação específica (doação, contribuição, convênio, parceria, auxílio } \\
\text { e subvenção através de convênios, editais, contratos, termos de parceiras e outros instrumentos) } \\
\text { são registradas em contas próprias, segregadas das demais contas da entidade. }\end{array}$ & 80 \\
\hline 14 & $\begin{array}{l}\text { Registram-se de forma segregada os benefícios concedidos a título de gratuidade, colocando em } \\
\text { destaque os que serão utilizados para prestação de contas ao governo. }\end{array}$ & 26,67 \\
\hline 15 & Constitui provisão para perdas esperadas. & 6,67 \\
\hline 16 & Incorpora o superávit ou déficit ao Patrimônio Social da entidade. & 26,67 \\
\hline 17 & Reconhece a gratuidade por meio da prestação de serviços pelo valor efetivamente praticado. & 0 \\
\hline 18 & $\begin{array}{l}\text { Segrega os registros contábeis de forma que se permita obter a apuração das informações para } \\
\text { prestação de contas aos órgãos governamentais e usuários externos. }\end{array}$ & 20 \\
\hline 19 & $\begin{array}{l}\text { Registra a dotação inicial de recursos pelo instituidor/fundador em ativos monetários como } \\
\text { doação patrimonial, com reconhecimento em conta do Patrimônio social. }\end{array}$ & \multirow{4}{*}{0} \\
\hline 20 & $\begin{array}{l}\text { Reconhece e registra o trabalho voluntário pelo valor justo da prestação do serviço, mesmo não } \\
\text { havendo desembolso financeiro. }\end{array}$ & \\
\hline 21 & Aplica aos ativos não monetários, Seção 27 da NBC TG 1000 e a NBC TG 01, quando aplicável. & \\
\hline 22 & $\begin{array}{l}\text { Em caso de adoção inicial da ITG } 2002 \text { e da NBC TG } 1000 \text { ou das normas completas (IFRS full), } \\
\text { a entidade pode adotar os procedimentos do custo atribuído (deemed cost) de que trata a ITG } 10 . \\
\text { É feito este reconhecimento. }\end{array}$ & \\
\hline
\end{tabular}

Fonte: Dados da pesquisa.

Concernente à categoria registros contábeis, doze entidades, o equivalente a $80 \%$ das entidades estudadas, registram receitas e despesas segregadas por atividade e reconhecem-nas em contas próprias, segregadas das demais contas. Apenas três (20\%) registram a subvenção, contribuição para 
custeio e investimento, isenção, incentivo fiscal em conta do passivo até o reconhecimento no resultado. Das 15 entidades, quatro $(26,67 \%)$ delas reconhecem de forma segregada os benefícios concedidos a título de gratuidade, colocando em destaque os que serão utilizados para prestação de contas ao governo.

Apenas a igreja " $F$ " $(6,67 \%)$, constitui provisão para perdas esperadas. Nenhuma entidade reconhece a gratuidade por meio da prestação de serviços pelo valor efetivamente praticado, bem como não registra a dotação inicial de recursos pelo instituidor/fundador em ativos monetários como doação patrimonial, com reconhecimento em conta do Patrimônio social. As entidades "A", " $\mathrm{F}$ ", " $\mathrm{K}$ " e "O" (26,67\%) incorporam o superávit ou déficit ao Patrimônio Social da entidade. Percebe-se que as entidades não fazem os devidos registros dos fatos ocorridos na instituição, principalmente quando o registro é pautado numa norma mais detalhista, como é visto nos itens 19 , 20, 21 e 22 do questionário (Quadro 5), que congregam além da ITG 2002, outros pontos tratados em outras normas.

Ao ponto em que o devido registro contábil em seu tempo oportuno aumenta o nível de transparência da entidade, de acordo com os resultados, infere-se que as entidades religiosas não estão efetivamente passando a sociedade ou órgãos competentes uma confiabilidade da aplicação dos recursos. Como aponta Portulhak, Delay e Pacheco (2015), o mecanismo da accountability valida as ações da organização e envereda a legitimidade desta perante as partes interessadas.

As ferramentas indispensáveis para avaliar a situação financeira e econômica de uma organização, independentemente de qual setor esteja inserida, são as demonstrações contábeis (Matarazzo, 2003). Nesta perspectiva, criou-se a categoria elaboração das demonstrações contábeis, que foi segregada em duas análises, a primeira visou verificar a devida elaboração pela entidade e no segundo momento, observar a empregabilidade correta da nomenclatura das contas em conformidade com a norma.

Quadro 6: Categoria elaboração das demonstrações contábeis

\begin{tabular}{|c|c|c|c|c|c|c|c|c|c|c|c|c|c|c|c|c|}
\hline Item & Demonstrações & \multicolumn{15}{|c|}{ INSTITUIÇÕES } \\
\hline \multirow{5}{*}{23} & & A & B & C & D & E & $\mathbf{F}$ & G & $\mathbf{H}$ & I & $\mathbf{J}$ & $\mathbf{K}$ & L & $\mathbf{M}$ & $\mathbf{N}$ & $\mathrm{O}$ \\
\hline & Balanço Patrimonial & $X$ & $x$ & & $X$ & & $X$ & & $X$ & & & & $x$ & $X$ & & $x$ \\
\hline & $\begin{array}{l}\text { Demonstração do } \\
\text { Superávit ou Déficit }\end{array}$ & $X$ & $X$ & & $X$ & $\mathrm{X}$ & $X$ & & $X$ & $X$ & $X$ & & $X$ & $X$ & $X$ & $\mathrm{X}$ \\
\hline & $\begin{array}{l}\text { Demonstração das } \\
\text { Mutações do Patrimônio } \\
\text { Social }\end{array}$ & $X$ & & & & & $X$ & & & & & & $X$ & & & \\
\hline & $\begin{array}{l}\text { Demonstração dos Fluxos } \\
\text { De Caixa }\end{array}$ & $X$ & & & & & $X$ & & $X$ & & & & $X$ & & & $x$ \\
\hline
\end{tabular}

Fonte: Dados da pesquisa.

Embora a norma contábil ITG 2002 não tenha caráter de exigência e sim de instrução ao tratamento contábil para as entidades sem finalidade de lucros, é fundamental para as organizações desse setor a elaboração de seus demonstrativos financeiros, uma vez que os recursos para manutenção são oriundos de doações de seus fieis ou de órgãos privados e públicos. Posto isso, verifica-se que das quinze entidades observadas, apenas três elaboram as demonstrações elencadas pela ITG 2002, e três delas não fazem nenhuma das demonstrações. As entidades " $\mathrm{E}$ ", "J" e " $\mathrm{N}$ " apresentam apenas a Demonstração do superávit ou déficit.

Quando um templo não elabora suas demonstrações contábeis deixa de prover aos usuários informações que retratam a situação econômico-financeira da organização, e ainda, dificulta a tomada de decisões por parte dos gestores por não possuir documentação que constate a forma em 
que os recursos estão sendo conduzidos. Neste ponto, assentindo Soares, Vicente e Linkes (2010), ressalta-se que as demonstrações contábeis se caracterizam como um mecanismo de gestão. Por menor que seja uma organização é preciso elaborar suas demonstrações contábeis, visto que é por meio da elaboração destes demonstrativos que se criam procedimentos de boas práticas gerenciais.

Ainda em relação à elaboração das demonstrações contábeis, o Quadro 7 destaca o uso correto da nomenclatura das contas aos respectivos demonstrativos e a classificação correta dos fatos contábeis. Os resultados expõem o percentual de cada item do questionário no que se refere aos pontos observados na categoria.

Quadro 7: Categoria elaboração das demonstrações contábeis (nomenclatura)

\begin{tabular}{|c|l|c|}
\hline Item & \multicolumn{1}{|c|}{ Descrição } & $\%$ \\
\hline 24 & $\begin{array}{l}\text { No Balanço Patrimonial são usadas as seguintes nomenclaturas: a) Patrimônio social; b) Superávit } \\
\text { ou déficit acumulado; C) São substituídos os termos lucro e prejuízo por superávit/déficit na DSD, } \\
\text { DMPL e DFC. }\end{array}$ & 80 \\
\hline 25 & $\begin{array}{l}\text { Destacam-se no resultado as informações de gratuidade concedidas e serviços voluntários obtidos } \\
\text { e divulgar em notas explicativas por tipo de atividade. }\end{array}$ & 0 \\
\hline 26 & Classificam-se as doações na DFC no fluxo de caixa operacional. & 20 \\
\hline
\end{tabular}

Fonte: Dados da pesquisa.

Em se tratando da nomenclatura apropriada para as demonstrações contábeis das entidades sem fins lucrativos, os resultados apontam que 12 entidades (80\%) adotam a nomenclatura correta nas suas demonstrações. Os templos " $\mathrm{C}$ ", " $\mathrm{G}$ " e " $\mathrm{K}$ " não atendem nenhum dos itens do questionário (24, 25 e 26), pois não elaboram nenhuma das demonstrações. Nenhuma das organizações destaca no resultado as informações de gratuidade e serviços voluntários, sendo assim, não divulga este fato nas notas explicativas. A classificação correta das doações no fluxo de caixa das atividades operacionais na Demonstração do Fluxo de Caixa é elaborada apenas pelas entidades " $A$ ", " $F$ " e " $L$ " (20\%).

A última categoria de análise aplicada para verificar a aderência das práticas contábeis das entidades dos tempos religiosos pernambucanos a ITG 2002 se refere à divulgação das informações em Notas Explicativas. Segundo Cruz (2010) nas organizações sem fins lucrativos, a divulgação das informações é útil para auxiliar os doadores na tomada de decisão de suas doações. Dessa forma, tal prática legitima as organizações do terceiro setor no tocante a transparência da aplicação e destinação dos recursos, no ensejo de tornar claro o uso dos recursos às partes interessadas seja por cumprimento a algum órgão ou norma ou de forma voluntária.

\begin{tabular}{|c|c|c|c|c|c|c|c|c|c|c|c|c|c|c|c|c|}
\hline \multirow{3}{*}{ Item } & \multicolumn{16}{|c|}{ Quadro 8: Categoria divulgação } \\
\hline & \multirow[t]{2}{*}{ Descrição } & \multicolumn{15}{|c|}{ INSTITUIÇÕES } \\
\hline & & $\mathbf{A}$ & B & $\mathrm{C}$ & D & $E$ & F & G & $\mathrm{H}$ & I & $\mathrm{J}$ & $\mathbf{K}$ & L & $\mathbf{M}$ & $\mathbf{N}$ & $\mathrm{O}$ \\
\hline 28 & $\begin{array}{l}\text { As demonstrações contábeis } \\
\text { são complementadas por meio } \\
\text { de notas explicativas. }\end{array}$ & $X$ & & & & & $x$ & & & & & & $x$ & & & \\
\hline
\end{tabular}

Fonte: Dados da pesquisa.

Quando questionadas pela prática de divulgação das informações contábeis complementares por meio das Notas Explicativas, somente $20 \%$ das entidades (" $\mathrm{A}$ ", " $\mathrm{F}$ " e "L") acusaram a realização deste ato. Os achados de Faria e Rego (2014) que analisaram práticas contábeis numa entidade religiosa do Estado da Bahia corroboram com os resultados desta pesquisa. Segundo os autores, apesar 
da entidade atuar com nível de transparência de suas finanças e manter escrituração contábil regular, não divulgam suas demonstrações contábeis para a comunidade, restringindo-se a divulgar apenas balanços simples com registros de entradas, saídas e saldos de recursos.

\section{CONCLUSÕES}

Esta pesquisa investigou o grau de aderência das entidades religiosas, quanto à ITG 2002, em suas práticas contábeis. Para tanto, utilizou-se da técnica survey e um questionário semiestruturado elaborado com base na norma supracitada, o qual foi respondido por uma amostra de representantes dos templos religiosos do Estado de Pernambuco.

As evidências encontradas constatam que as práticas contábeis estabelecidas pela ITG 2002 não foram seguidas em sua totalidade por nenhuma das entidades religiosas investigadas no estudo. Cabe salientar o não cumprimento por parte dos templos religiosos quanto às obrigações acessórias para obtenção da imunidade apontada na Constituição Federal. Ressalta-se, ainda, que apenas 20\% das entidades religiosas estudadas elaboram as demonstrações contábeis e divulgam suas informações por meio de Notas Explicativas, revelando a falta de transparência para com a os doadores de recursos e a comunidade.

Assim, faz-se necessário uma maior atenção por parte daqueles que vivenciam as práticas operacionais dessas organizações, bem como pelos órgãos fiscalizadores e de todos que possuem interesse em manter a credibilidade e o prestígio da profissão contábil perante a sociedade. Dessa forma, ressalta-se a relevância da divulgação a essas entidades sobre a interpretação técnica pertinente, apresentando a importância de se elaborar demonstrativos de recursos que fluem para a entidade como ferramenta de gestão e transparência e o seguimento da norma tratada neste trabalho.

Com relação às limitações da pesquisa, cita-se: (i) a dificuldade de acesso aos templos religiosos; e, (ii) um número pequeno de entidades estudadas. Assim, sugere-se que estudos futuros, possam ser realizados, considerando: (i) ampliação da amostra e contemplação de outras convenções religiosas, (ii) realizar o estudo com outras unidades da federação, visando investigar se o nível de aderência quanto a ITG 2002, bem como a ausência de divulgação e transparência por parte das entidades do terceiro setor é uma prática comum no âmbito nacional.

\section{REFERÊNCIAS}

Araújo, O. C. (2005). Contabilidade para organizações do terceiro setor. São Paulo: Atlas.

Bardin, L. (2007). Análise de conteúdo (L. A. Rego \& A. Pinheiro, Trads.). Lisboa: Edições 70.

Boedau, A. V., \& Lima, L. M. (2008). Importância da contabilidade para o terceiro setor. São Paulo: M.A.S.

Brasil. (1911). República e Laicidade: Lei da separação da igreja do estado. Recuperado em 10 junho, 2014, de http://www.laicidade.org/documentacao/legislacao-portuguesa/portugal/republica1910-1926/lei-da-separacao-da-igreja-do-estado/.

Brasil. (1988). Constituição da República Federativa do Brasil de 1988. Recuperado em 11 junho, 2014, de http://www.planalto.gov.br/ccivil_03/constituicao/constituicaocompilado.htm.

Brasil. (2002). Código civil brasileiro. Recuperado em 23dezembro, 2013, de http://www.planalto.gov.br/ccivil_03/leis/2002/L10406.htm.

Burchell, S., Clubb, C., \& Hopwood, A. G. (1985). Accounting in its Social Context: Towards a History of Value Added in the United Kingdom'Accountin. Organizations and Society, pp. 341-413.

Camargo, M. F. (2001). Gestão do terceiro setor no Brasil. São Paulo: Futura. 
Carneiro, A. F., Oliveira, D. L., \& Torres, L. C. (2001). Accountability e prestação de contas das organizações do terceiro setor: uma abordagem à relevância da contabilidade. Sociedade, Contabilidade e Gestão, 6(2), pp. 90-105.

CFC. (2012). Interpretação Técnica ITG 2002. Recuperado em 12junho, 2014, de http://www.cfc.org.br/sisweb/sre/detalhes_sre.aspx?Codigo=2012/001409.

CFC. (2012). Obrigatoriedade da escrituração contábil. Recuperado em 12 de Junho, 2014, de http://portalcfc.org.br/coordenadorias/camara tecnica/faq/faq.php?Id=1879.

Coliath, G. C. (2014). A contabilidade como ciência social e sua contribuição para o capitalismo. Revista ENIAC Pesquisa, 3(2), 152-161.

Corrêa, V. S., \&Vale, G. M. V. (2017) Ação econômica e religião: Igrejas como empreendimentos no Brasil. Revista de Administração Contemporânea, 21(1), 1-18.

Cruz, C. V. O. A. (2010). A relevância da informação contábil para os investidores sociais privados de entidades do terceiro setor no Brasil: uma investigação empírica. Tese de Doutorado (Doutora em Controladoria e Contabilidade). São Paulo: Universidade de São Paulo.

EFF (novembro, 2015). Vaticano é acusado de desvio de dinheiro e gastos excessivos. Recuperado em 07 de julho de 2017, de http://odia.ig.com.br/noticia/mundoeciencia/2015-11-03/vaticano-e-acusado-de-desvio-de-dinheiro-e-gastos-excessivos.html.

Falconer, A. P. (1999). A promessa do terceiro setor: um estudo sobre a construção do papel das organizações sem fins lucrativos e do seu campo de gestão. Dissertação de Mestrado (Mestre em Administração). São Paulo: Universidade de São Paulo.

Faria, J. A., \& Rego, A. L. S. (2014). Transparência nas entidades religiossas: um estudo de caso sobre a aplicação de fatores que cotribuem para a transparência financeira na paróquia senhor do bonfim. Revista Teologia e Ciências da Religião, 4(1), pp. 267-299.

Favero, H. L., Lonardoni, M., Souza, C., \& Takamura, M. (2011). Contabilidade: teoria e prática (16 ed.). São Paulo: Atlas.

Fernandes, V. (abril, 2016). Receita cobra quase R\$ 23 milhões por fraude em Igreja Maranata no ES. Recuperado em 07 de julho de 2017, de http:/g1.globo.com/espiritosanto/noticia/2016/04/receita-cobra-quase-r-23-milhoes-por-fraude-em-igreja-maranata-noes.html.

Flick, U. (2009). Introdução à pesquisa qualitativa (3ª ed., J. E. Costa, Trad.). São Paulo: Artmed.

Folha de São Paulo (2010). Procuradoria pede condenação da Fundação Renascer e ex-bispo por desvio de dinheiro. Recuperado em 07 de julho de 2017, de http://www1.folha.uol.com.br/poder/2010/08/783655-procuradoria-pede-condenacao-da-fundacao-renascer-e-ex-bispo-pordesvio-de-dinheiro.shtml.

Freeman, R. J., \&Shoulders, C. D. (1993) Governmental and nonprofit accounting: theory and practice.

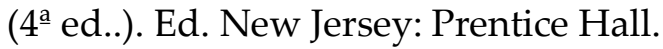

Gomes, D. R. (2000). A evolução dos registros contabilísticos e a aplicação da partida dobrada em Portugal. Dissertação de Mestrado (Mestre em Contabilidade e Auditoria). Braga: Escola de Economia e Gestão da Universidade do Minho.

Hardy, L., \& Ballis, H. (2013). Accountability and giving accounts informal reporting practices in a religious corporation. Accounting, Auditing \& Accountability Journal, 26(4), pp. 539-566. 
Ihemeje, J. C., Okereafor, G., \& Ogungbangbe, B. M. (2015). The use of accounting system in the Nonprofit-Oriented Church Organizations of Nigeria. International Journal of Management Science and Business Administration, 1(12), pp. 58-66.

Kothe, A. C. C. L., Sousa, L. A., \& Gozer, I. C. (2009). Orçamento em entidades sem fins lucrativos: estudo de caso em uma entidade religiosa. Rev. Ciênc. Empres. UNIPAR, 10(1), pp. 69-98.

Iudícibus, S., Martins, E., Gelbcke, E. R., \& Santos, A. (2010). Manual de Contabilidade Societária (1aㅗ ed.). São Paulo: Atlas.

Laughlin, R. C. (1988). Accounting in its social context: an analysis of the accounting systems of the Church of England. Accounting, Auditing \& Accountability Journal, 1(2), pp. 19-42.

Lehman, J. F., \& Mehrens, W. A. (1971).Educational research: readings in focus. New York: Holt, Rineart \& Winston.

Matarazzo, D. C. (2003). Análise financeira de balanços: abordagem básica e gerencial. (6-a ed.). São Paulo: Atlas.

Mendonça, L. R., \&Machado Filho, C. A. P. (2004) Governança nas organizações do terceiro setor: considerações teóricas. Revista de Administração da Universidade de São Paulo, 39(4), 302-308.

Nascimento, A. M., \& Reginato, L. (2008). Divulgação da informação contábil, governança corporativa e controle organizacional: uma relação necessária. Revista Universo Contábil, 4(3), pp. 25-47.

Olak, P. A., \& Nascimento, D. T. (2010). Contabilidade para entidades Sem Fins Lucrativos (Terceiro Setor) ( $3^{\mathrm{a}}$ ed.). São Paulo: Atlas.

Oliveira, A., \& Romão, V. (2011). Manual do terceiro setor e instituições religiosas (3 $3^{\mathrm{a}}$ ed.). São Paulo: Atlas.

Paixão, J. C., \& Lourenço, A. (1994). Contos do Reino e da Casa. Lisboa: Tribunal de Contas.

Portulhak, H., Delay, A. J., \&Pacheco, V. (2015) Prestação de contas por entidades do terceiro setor e seus impactos na obtenção de recursos: um olhar sobre o comportamento dos doadores individuais. Pensar Contábil, 17(64), 39-47.

Saunders, M., Lewis, F., \& Thornhill, A. (2016). Research methods of business students. (7ª ed.). England: Pearson.

Soares, L. L., Vicente, E. F. R., \&Lunkes, R. J. (2010). Controles internos em pequenas comunidades católicas de Florianópolis. Sociedade, Contabilidade e Gestão, 5(Especial), pp. 67-83.

Triviños, A. N. S. (1987). Introdução à pesquisa em ciências sociais: a pesquisa qualitativa em educação. São Paulo, Atlas.

Vergara, S. C. (2006). Projetos e relatórios de pesquisa em Administração. (7ª ed.). São Paulo: Atlas. 